Short Communication

\title{
Investigation of the cyanosilylation catalysed by metal-siliceous catalysts
}

\author{
Selvedin Telalović, Ulf Hanefeld * \\ Gebouw voor Scheikunde, Technische Universiteit Delft, Julianalaan 136, 2628 BL Delft, The Netherlands
}

\section{A R T I C L E I N F O}

Article history:

Received 19 August 2010

Received in revised form 15 October 2010

Accepted 15 November 2010

Available online 23 November 2010

\section{Keywords:}

Mesoporous materials

TUD-1

Al-MCM-41

Cyanosilylation

Acetophenone

Heterogeneous catalysis

\begin{abstract}
A B S T R A C T
Different amorphous mesoporous TUD-1 catalysts were employed in cyanosilylation of acetophenone with trimethylsilylcyanide in dichloromethane at room temperature. Catalysts were monometallic Al-TUD-1, ZrTUD-1 and bimetallic Na-Al-TUD-1 and Al-Zr-TUD-1's with constant Si/metal ratio but different $\mathrm{Al} / \mathrm{Zr}$ ratios. Al-TUD-1 proved to be the most active TUD-1 catalyst. Introduction of sodium or Lewis acidic Zr into Al-TUD-1 to achieve synergistic properties did not lead to increased activity. During the reaction we observed silylation of the catalysts as proven by FT-IR and cross-polarization MAS-NMR analysis. The best results were achieved using Al-MCM-41 catalysts due to their higher degree of order and well defined narrow pore size. However, this catalyst was silylated, too.
\end{abstract}

(c) 2010 Elsevier B.V. All rights reserved.

\section{Introduction}

The cyanosilylation of carbonyl compounds to form new C-C bonds and to protect alcohol functions is an important reaction as the $O$-protected cyanohydrins can be transformed into a wide range of important intermediates such as $\alpha$-hydroxy acids, $\alpha$-amino acids and $\beta$-amino alcohols [1]. The reaction is mostly catalysed by homogeneous Lewis acids or base catalysts. However in the last two decades heterogeneous catalysis has gained considerable ground [2,3]. One of very successful heterogeneous examples used in cyanosilylation reaction is Al-MCM-41 [4]. In cyanosilylation of different aldehydes as well as ketones Al-MCM-41 was not only very active (only $5 \mathrm{mg}$ catalyst was needed to convert $1 \mathrm{mmol}$ benzaldehyde within $1 \mathrm{~min}$ ) but also recyclable. In contrast, amorphous aluminosilicates showed almost no activity regardless of the $\mathrm{Si} / \mathrm{Al}$ ratio. The high activity of Al-MCM-41 was explained by the possible cooperation between acid sites and basic sites originating from the presence of minor amounts of sodium [4].

MCM-41 with its honeycomb structure has one-dimensional pores, which might lead to diffusion limitations. Furthermore its synthesis requires large amounts of surfactants. In contrast the wellestablished, amorphous three-dimensional TUD-1 with a high surface area and pore size can be synthesized without surfactants $[5,6]$. Due to these advantages we investigated how amorphous TUD-1 catalysts, containing $\mathrm{Al}$ and/or $\mathrm{Zr}$ would behave in this reaction $[7,8]$. Both sodium containing and sodium free TUD-1 catalysts were employed

\footnotetext{
* Corresponding author. Tel.: +31 1527893 04; fax: +31 152781415. E-mail address: u.hanefeld@tudelft.nl (U. Hanefeld).
}

and compared with Al-MCM-41 containing different amounts of sodium. In this manner insight into the catalytic mechanism should be obtained. In addition to well-established Al-TUD-1, Na-Al-TUD-1 was synthesized for the first time to test the proposed interaction between Brønsted acid sites and basic sites originating from the presence of sodium.

\section{Experimental}

For details on catalysts preparation and characterisation see Supplemental data.

\subsection{Catalytic tests}

\subsubsection{Cyanosilylation reaction}

TUD- 1 catalysts were calcined at $600{ }^{\circ} \mathrm{C}$ for $10 \mathrm{~h}$ with a ramp rate of $1{ }^{\circ} \mathrm{C} \mathrm{min}^{-1}$ [7]. MCM-41 catalysts were dried at $120^{\circ} \mathrm{C}$ for $1 \mathrm{~h}$ under vacuum. Dry $\mathrm{CH}_{2} \mathrm{Cl}_{2}(10 \mathrm{~mL})$ was added to calcined or dried catalysts $(50 \mathrm{mg})$ followed by acetophenone $(1 \mathrm{mmol}, 0.12 \mathrm{~g})$ and the internal standard dodecane $(1 \mathrm{mmol}, 0.17 \mathrm{~g})$. The reaction was started by addition of trimethylsilylcyanide ( $5 \mathrm{mmol}, 0.49 \mathrm{~g}$ ) at room temperature and under $\mathrm{N}_{2}$ atmosphere. The reaction was followed by taking aliquots $(20 \mu \mathrm{L})$ every 5, 15, 30, 45 min and then every 1, 2, 3, 5 and $7 \mathrm{~h}$. Samples were analysed by GC, a Shimadzu GC-17A gas chromatograph, equipped with a $25 \mathrm{~m} \times 0.32 \mathrm{~mm} \times 0.25 \mu \mathrm{m}$ column Chrompack Chirasil-Dex CB, He was used as carrier gas. Employing an isotherm $\left(130{ }^{\circ} \mathrm{C}\right)$ the following retention times were recorded: acetophenone (1.75 $\mathrm{min})$, dodecane (3.03 $\mathrm{min}$ ) and 2-trimethylsilyloxy-2-phenylpropanenitrile (4.55 min). For all of the reactions the selectivity was more than $99 \%$. 


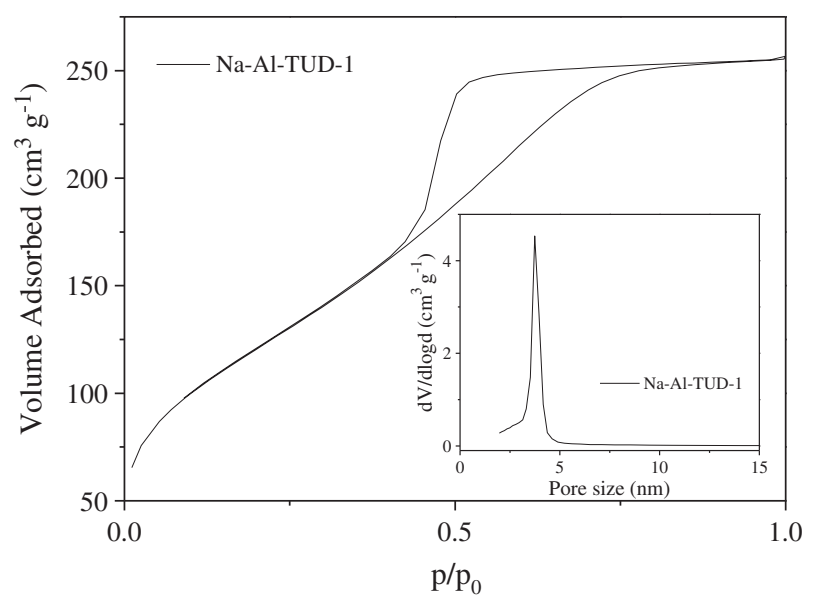

Fig. 1. Isotherm of $\mathrm{Na}-\mathrm{Al}-\mathrm{TUD}-1$ obtained from $\mathrm{N}_{2}$ physisorption analysis (inset, pore size distribution).

\subsubsection{Cyanosilylation reaction with TMSCN treated catalysts}

To calcine TUD- 1 catalysts $\left(50 \mathrm{mg}, 600{ }^{\circ} \mathrm{C}, 10 \mathrm{~h}\right.$, and $1{ }^{\circ} \mathrm{C} \mathrm{min}-1$ ) $10 \mathrm{~mL}$ dry $\mathrm{CH}_{2} \mathrm{Cl}_{2}$ and $5 \mathrm{mmol}$ trimethylsilylcyanide (TMSCN) were added. The entire mixture was left stirring for $30 \mathrm{~min}$. Subsequently the liquid layer was removed with a syringe equipped with a cotton plug and the catalyst was washed with $10 \mathrm{~mL}$ dry $\mathrm{CH}_{2} \mathrm{Cl}_{2}$. Directly after the TMSCN pre-treatment catalysts were employed in cyanosilylation reaction as described earlier.

Al-MCM-41 catalysts were dried at $120^{\circ} \mathrm{C}$ for $1 \mathrm{~h}$ at vacuum conditions. To the dried catalysts $(150 \mathrm{mg}) 30 \mathrm{~mL}$ dry $\mathrm{CH}_{2} \mathrm{Cl}_{2}$ was added at room temperature under $\mathrm{N}_{2}$ atmosphere. Silylation was started by the addition of trimethylsilylcyanide $(2 \mathrm{~mL})$. After $30 \mathrm{~min}$ the reaction was filtered and extensively washed with dry $\mathrm{CH}_{2} \mathrm{Cl}_{2}(5 \times$, in total $50 \mathrm{~mL}$ ). Finally the catalysts were dried at $100{ }^{\circ} \mathrm{C}$ for $1 \mathrm{~h}$ under vacuum and stored under $\mathrm{N}_{2}$ to be used later in cyanosilylation under conditions as described earlier.

\section{Results and discussion}

Na-Al-TUD-1 exhibits an intense peak at $0.5^{\circ}(2 \theta)$ in the X-ray diffractogram like all mesostructured TUD-1 materials (Fig. S1 of the Supplementary data) $[5,6]$. In addition Na-Al-TUD-1 displays a broad peak around $25^{\circ}(2 \theta)$ indicating its amorphous nature. No evidence of crystalline $\mathrm{Al}_{2} \mathrm{O}_{3}$ phases was found in the X-ray diffractograms, suggesting that the aluminium was incorporated into the framework. The Na-Al-TUD-1 shows also a typical Type IV isotherm with a type H1 hysterisis loop characteristic for mesoporous materials (Fig. 1). This is pointed out by a large uptake of $\mathrm{N}_{2}$ at relative pressures between 0.4 and $0.8 \mathrm{p} / \mathrm{p}_{0}$ due to capillary condensation in the mesopores. Pore size distribution deduced from desorption gives a narrow pore size distribution with a maximum at $3 \mathrm{~nm}$ (Fig. 1, inset). The surface area and pore volume are lower than in Al-TUD-1 sample (Table 1 ). Around $50 \%$ of aluminium is tetrahedrally coordinated (Fig. S2 of the Supplementary data), while the rest of the aluminium is penta- and hexacoordinated.

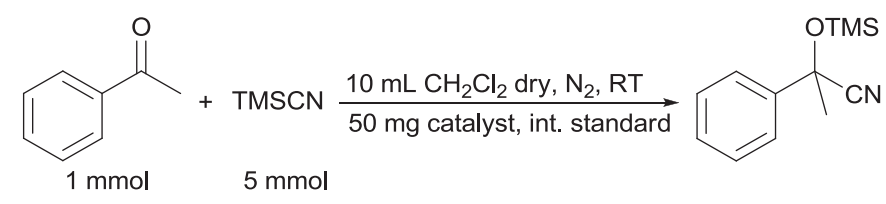

Scheme 1. Cyanosilylation of acetophenone with trimethylsilylcyanide.

Al-MCM-41 and an additional sample of Al-MCM-41 with a lower amount of sodium (obtained by treatment of calcined Al-MCM- 41 with $1 \mathrm{M} \mathrm{NH}_{4} \mathrm{NO}_{3}$ ) denoted as Al-MCM-41-P were prepared according to the literature [9]. The Al-MCM-41-P sample has a lower amount of sodium and also reduced surface area, pore size as pore volume (Table 1, entries 3 and 4, Fig. S3 of the Supplementary data). ${ }^{27} \mathrm{Al}-\mathrm{NMR}$ analysis revealed that Al-MCM-41 sample contained 58\% tetrahedrally coordinated aluminium (Fig. S4 of the Supplementary data).

To probe the catalysts to the full the ketone acetophenone was chosen as a model compound for the cyanosilylation as it is more difficult to convert than aldehydes (Scheme 1) [1]. The catalysts tested also included Zr-TUD-1 and bimetallic Al-Zr-TUD-1 catalysts with different $\mathrm{Al} / \mathrm{Zr}$ ratios; previously synthesized and characterised $[8,10]$. Al-TUD-1 was the most active catalyst (Fig. 2) of the TUD-1 type. In the case of bimetallic $\mathrm{Al}-\mathrm{Zr}$-TUD-1 catalysts the more $\mathrm{Al}$ was present the more active the catalyst was. Synergistic interaction between Lewis acid sites imparted due to the presence of different metals and Brønsted acid sites originating from the presence of $\mathrm{Al}$ could not be observed. Introduction of sodium into Al-TUD-1 considerably reduced its activity. This is in contradiction of the hypothesis that sodium plays an activating role in this reaction. The same was the case if Al was replaced by Zr (Zr-TUD-1). Both Zr-TUD-1 and Na-Al-TUD-1 display a lag during the first half an hour, obviously the active catalytic species first needs to be released. Acetophenone was added first in the catalytic experiments. It coordinates to Lewis acids sites, $\mathrm{Zr}$ or Al, making the surface hydrophobic and inhibiting the catalytic species originating from interaction between trimethylsilylcyanide and Lewis acid sites.

The best results were obtained with Al-MCM-41 catalysts (Fig. 2), whether or not pre-treated in order to remove the sodium. Within half an hour complete conversion was attained. This again indicates that $\mathrm{Na}$ does not play an important role in the catalysis. It also demonstrates that diffusion is a parameter of no importance in this reaction, given the fact that the difference in surface area between the two MCM-41 based catalysts is around $200 \mathrm{~m}^{2} \mathrm{~g}^{-1}$ (Table 1). Catalysts containing aluminium, i.e. Brønsted acid sites and Lewis acid sites, were the most active.

As the results obtained with all catalysts could not be reproduced when TMSCN was added prior to acetophenone, we suspected that silylation of surface $\mathrm{OH}$ groups was the source of this discrepancy. In Fig. 3 catalysts pre-treated with TMSCN prior to cyanosilylation of acetophenone showed greatly decreased reactivity. The loss of activity was most pronounced for TMSCN pre-treated Al-MCM-41. While Al-TUD-1 with its three-dimensional pore structure in this case was the best catalyst, Al-MCM-41 displayed very little activity. Only Zr-TUD-1 and the Al-Zr-TUD-1's with a large $\mathrm{Zr}$ to Al ratio performed worse than Al-MCM-41.

Table 1

ICP and $\mathrm{N}_{2}$-physisorption results of TUD- 1 and MCM-41 based catalysts.

\begin{tabular}{|c|c|c|c|c|c|c|c|c|}
\hline M-TUD-1 & $\mathrm{n}_{\mathrm{S} /(\mathrm{Al}+\mathrm{Zr})}^{\mathrm{a}}$ & $\mathrm{n}_{\mathrm{Si} / \mathrm{Al}}^{\mathrm{a}}$ & $\mathrm{n}_{\mathrm{S} i / \mathrm{Zr}}^{\mathrm{a}}$ & $\mathrm{n}_{\mathrm{Al} / \mathrm{Na}}^{\mathrm{a}}$ & $\mathrm{S}_{\mathrm{BET}}\left(\mathrm{m}^{2} \mathrm{~g}^{-1}\right)$ & $\mathrm{d}_{\mathrm{P}, \mathrm{BJH}}(\mathrm{nm})$ & $V_{\mathrm{P}, \mathrm{BJH}}\left(\mathrm{cm}^{3} \mathrm{~g}^{-1}\right)$ & OH Content $\left(\mathrm{mmol} \mathrm{g}^{-1}\right)^{\mathrm{f}}$ \\
\hline Al-TUD-1 ${ }^{\mathrm{b}}$ & 26.6 & 26.6 & - & - & 760 & 3 & 0.75 & 1.5 \\
\hline Na-Al-TUD-1 ${ }^{\mathrm{c}}$ & 4.1 & 4.1 & - & 3.5 & 441 & 3 & 0.40 & 3.4 \\
\hline Al-MCM-41 & 26.0 & 26.0 & - & 5.5 & 1052 & 3 & 0.945 & 1.9 \\
\hline Al-MCM-41-P & 29.8 & 29.8 & - & 12.1 & 863 & 2.7 & 0.732 & 1.9 \\
\hline Al3Zr1-TUD-1 ${ }^{\mathrm{d}}$ & 28 & 34 & 142 & - & 685 & 3.3 & 0.57 & 1.8 \\
\hline Al1Zr1-TUD-1 ${ }^{\mathrm{d}}$ & 31 & 53 & 73 & - & 735 & 3.3 & 0.61 & 1.8 \\
\hline Al1Zr3-TUD- $1^{\mathrm{d}}$ & 33 & 103 & 48 & - & 667 & 4.4 & 0.65 & 1.9 \\
\hline Zr-TUD- $1^{\mathrm{e}}$ & 24.7 & - & 24.7 & - & 792 & 4 & 0.76 & 2.0 \\
\hline
\end{tabular}

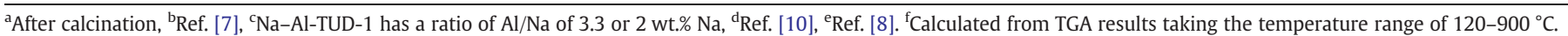




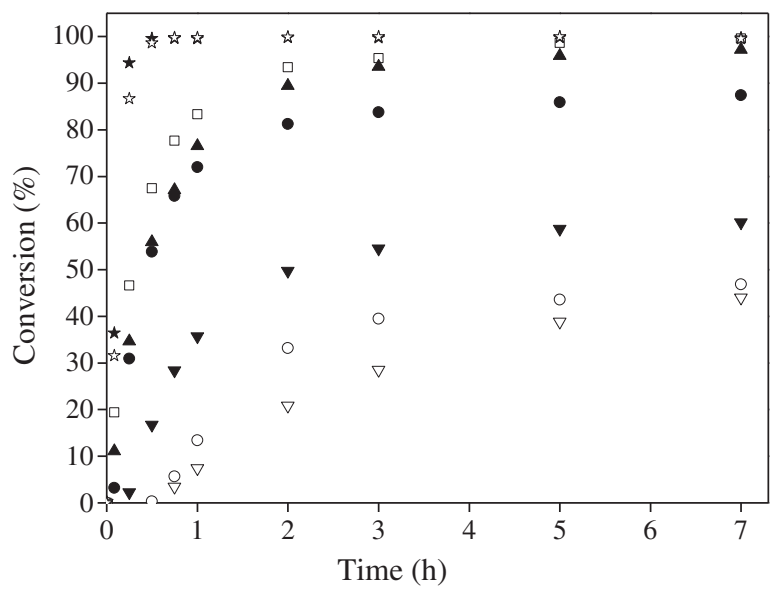

Fig. 2. The activity of TUD- 1 and MCM- 41 catalysts in the cyanosilylation of acetophenone with TMSCN. Reaction conditions: acetophenone $(1 \mathrm{mmol})$, TMSCN $(5 \mathrm{mmol})$, catalyst (50 mg), $\mathrm{CH}_{2} \mathrm{Cl}_{2}\left(10 \mathrm{~mL}\right.$ ), $\mathrm{N}_{2}$, RT. ( $\star$ ) Al-MCM-41, (文) Al-MCM-41-P, ( $\square$ ) Al-TUD-1,

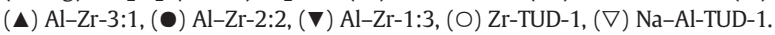

The silylation of surface $\mathrm{OH}$ groups was proven by FT-IR. In the pretreated sample of $\mathrm{Al}-\mathrm{MCM}-41$, the characteristic $\mathrm{OH}$ signal in the range $3800-3000 \mathrm{~cm}^{-1}$ has largely disappeared (Fig. 4 and Fig. S5 of the Supplementary Information). The same observation was made with the other catalysts.

In addition we also performed ${ }^{29} \mathrm{Si}$ MAS-NMR cross-polarization measurements. In all samples we could clearly distinguish $\mathrm{OSiMe}_{3}$ groups formed on the surface of the catalyst at 14 ppm (Fig. 5 and Fig. S6 of the Supplementary Information) [11]. This rigorously proves that TMSCN protects the silanol groups. Since CN is known to be a pseudo halogen, TMSCN obviously acts just like TMSCl on siliceous materials.

From the TGA results the $\mathrm{OH}$ content of the materials was calculated (Table 1 and Fig S7 of the Supplementary Information) to vary from 1.5 to $3.4 \mathrm{mmol} \mathrm{g}^{--1}$ for all catalysts used. These values are somewhat larger than those calculated using results from pyridine FT-IR in the case of MCM- 41 based materials. There weakly acidic $\mathrm{OH}$ groups have been determined to be around $0.7 \mathrm{mmol} \mathrm{g}^{-1}$ [12]. The difference can be explained by the difference in techniques used. Using more than $5 \mathrm{mmol}$ TMSCN per $50 \mathrm{mg}$ catalysts ensures complete coverage of this surface $\mathrm{OH}$ groups. The difference in catalytic performance between Al-TUD-1 and Al-MCM-41 TMSCN pre-treated catalysts can only be explained by the open three-dimensional structure of TUD-1 materials (Fig. 3).

It has previously been shown than hetero-polyacids such as dodecatungstophosphoric acid $\left(\mathrm{H}_{3} \mathrm{PW}_{12} \mathrm{O}_{40}\right)$ [13] employed as solid Brønsted

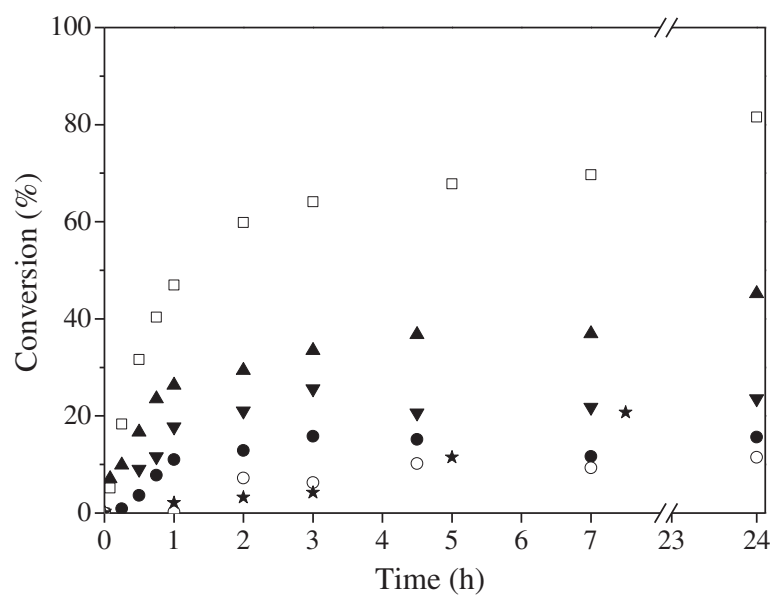

Fig. 3. The activity of TUD- 1 and MCM- 41 catalysts in cyanosilylation of acetophenone after TMSCN pre-treatment. Reaction conditions same as in Fig. 2. ( $\star$ ) Al-MCM-41, ( $\square$ ) Al-TUD-1, (ム) Al-Zr-3:1, (•) Al-Zr-2:2, ( $)$ Al-Zr-1:3, (O) Zr-TUD-1.

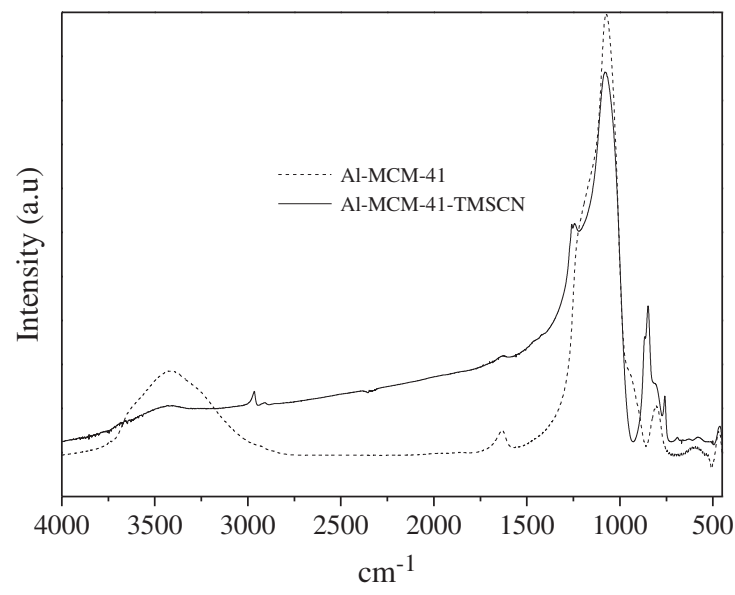

Fig. 4. FT-IR measurements of Al-MCM-41 before and after treatment with TMSCN.

acid or protic $\mathrm{CF}_{3} \mathrm{SO}_{3} \mathrm{H}[3]$ can catalyse the cyanosilylation. Moreover also the Lewis acidic silylated triflic acid, $\mathrm{CF}_{3} \mathrm{SO}_{3} \mathrm{SiMe}_{3}$ is able to catalyse the reaction; which led to a proposal of a mechanism in which TMSCN reacts with Brønsted acid sites to generate a trimethylsilyl cation like Lewis acid site [3]. As both Al-TUD-1 and Al-MCM-41 according to ${ }^{27} \mathrm{Al}-\mathrm{NMR}$ analysis contain similar amount of tetrahedrally coordinated aluminium (Si/Al ratio being in both cases 26) and therefore similar amount of Brønsted acid sites, the exceptionally high activity of Al-MCM-41 can only be explained by its ordered structure. The influence of the order in a heterogeneous catalyst has recently also been shown for Al-MCM-41 applied in Mukaiyama aldol reaction [14]. Al-MCM-41 submitted to mechanical compression lost their intrinsic order and was therefore much less active [14].

While amorphous $\mathrm{SiO}_{2}-\mathrm{Al}_{2} \mathrm{O}_{3}$ with $\mathrm{Si} / \mathrm{Al}$ ratios of 2,5 or 20 were not active at all, [4] the activity of aluminium increased with increase of order of the material from Al-TUD-1 to Al-MCM-41. Al-TUD-1, even though amorphous is however also mesoporous and three-dimensional and therefore more structured and active than amorphous $\mathrm{SiO}_{2}-\mathrm{Al}_{2} \mathrm{O}_{3}$. Ordered or not, all catalysts are silylated by TMSCN, strongly influencing their reactivity. The presence of both Lewis acid sites and Brønsted acids sites as is the case in Al-TUD-1 and Al-MCM-41 is essential for their high activity compared to other catalysts.

\section{Conclusion}

In conclusion, the reagent TMSCN reacts with silanol groups of the siliceous material. Silyation of the surface leads to greater inhibition in case of two-dimensional Al-MCM-41 than three-dimensional Al-TUD-1.

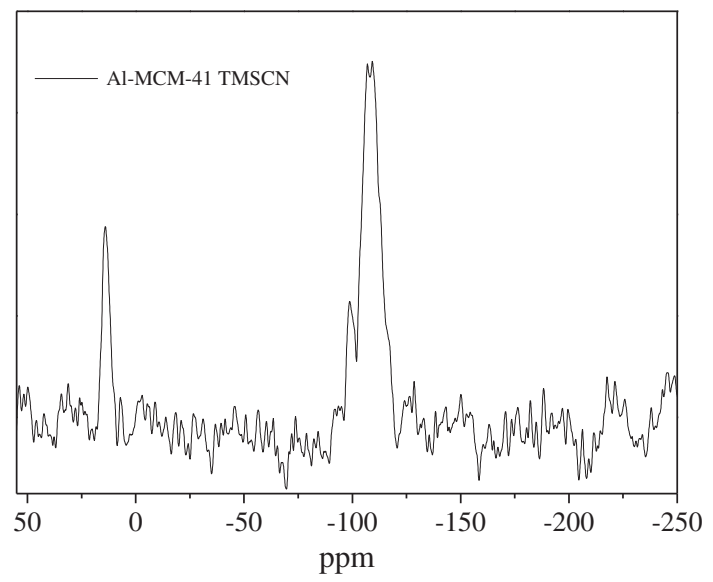

Fig. 5. Cross-polarization ${ }^{29} \mathrm{Si}$ MAS-NMR of Al-MCM-41 after TMSCN treatment. 
Sodium does not have a positive effect on the catalysis. The presence of Lewis and Brønsted acid sites as is the case in the monometallic aluminium based catalysts gives best catalytic results. In addition, the most important parameter for activity is the degree of order of the material, the higher the order the more active the catalyst.

\section{Acknowledgements}

This research was financially supported by a Mozaïek grant from NWO (Netherlands Organisation for Scientific Research). We thankS. Ajaikumar for his help with the synthesis of Al-MCM-41 and A. Ramanathan for its samples of Zr-TUD-1 and Al-Zr-TUD-1.

\section{Appendix A. Supplementary data}

Supplementary data to this article can be found online at doi:10.1016/j.catcom.2010.11.012.

\section{References}

[1] (a) M. North, D.L. Usanov, C. Young, Chem. Rev. 108 (2008) 5146;

(b) F.L. Cabirol, A.E.C. Lim, U. Hanefeld, R.A. Sheldon, I.M. Lyapkalo, J. Org. Chem. 73 (2008) 2446;

(c) J. Holt, U. Hanefeld, Curr. Org. Synth. 6 (2009) 15.

[2] (a) K. Sukata, Bull. Chem. Soc. Jpn 60 (1987) 3820;

(b) M. Onaka, K. Higuchi, K. Sugita, Y. Izumi, Chem. Lett. (1989) 1393; (c) K. Higuchi, M. Onaka, Y. Izumi, J. Chem. Soc. Chem. Commun. (1991) 1035;

(d) Y. Izumi, M. Onaka, J. Mol. Catal. 74 (1992) 35;

(e) B.M. Choudary, N. Narender, V. Bhuma, Synth. Commun. 25 (1995) 2829;

(f) M. Curini, F. Epifano, M.C. Marcotullio, O. Rosati, M. Rossi, Synlett (1999) 315;

(g) B. He, Y. Li, X. Feng, G. Zhang, Synlett (2004) 1776;

(h) M.L. Kantam, P. Sreekanth, P.L. Santhi, Green Chem. (2000) 47;

(i) C. Beleizão, B. Gigante, D. Das, M. Alvaro, H. Garcia, A. Corma, Chem. Commun. (2003) 1860;

(j) A. Procopio, G. Das, M. Nardi, M. Oliverio, L. Pasqua, ChemSusChem 1 (2008) 916;

(k) B. Karimi, L. Ma'Mani, Org. Lett. 6 (2004) 4813;

(l) S. Huh, H.-T. Chen, J.W. Wiench, M. Pruski, V.S.Y. Lin, Angew. Chem. Int. Ed. 44 (2005) 1826;

(m) C. Beleizão, B. Gigante, D. Das, H. Garcia, A. Corma, J. Catal. 221 (2004) 77.

[3] K. Higuchi, M. Onaka, Y. Izumi, Bull. Chem. Soc. Jpn 66 (1993) 2016.

[4] K. Iwanami, J.-C. Choi, B. Lu, T. Sakakura, H. Yasuda, Chem. Commun. (2008) 1002

[5] J.C. Jansen, Z. Shan, L. Marchese, W.Zhou, N.v.d. Puil, T. Maschmeyer, Chem. Commun (2001) 713.

[6] S. Telalović, A. Ramanathan, G. Mul, U. Hanefeld, J. Mater. Chem. 20 (2010) 642.

[7] R. Anand, R. Maheswari, U. Hanefeld, J. Catal. 242 (2006) 82.

[8] A. Ramanathan, M.C.C. Villalobos, C. Kwakernaak, S. Telalović, U. Hanefeld, Chem. Eur. J. 14 (2008) 961.

[9] H. Nur, H. Hamid, S. Endud, H. Hamdan, Z. Ramli, Mater. Chem. Phys. 96 (2006) 337.

[10] S. Telalović, J.F. Ng, R. Maheswari, A. Ramanathan, G.K. Chuah, U. Hanefeld, Chem. Commun. (2008) 4631.

[11] J.K.F. Buijink, J.J.M. van Vlaanderen, M. Crocker, F.G.M. Niele, Catal. Today 93-95 (2004) 199.

[12] A. Jentys, K. Kleestorfer, H. Vinek, Micro. Meso. Mater. 27 (1999) 321-328.

[13] H. Firouzabadi, N. Iranpoor, A.A. Jafari, J. Organomet, Chem. 690 (2005) 1556.

[14] K. Iwanami, T. Sakakura, H. Yasuda, Catal. Commun. 10 (2009) 1990. 